\title{
Research on the Innovation and Practice of the Teaching Model of Linear Algebra Based on Flipped Classroom
}

\author{
Shuxian Deng ${ }^{\mathrm{a}}$ and Xizhuan Shi ${ }^{\mathrm{b}^{*}}$ \\ Information engineering college, Department of mathematics and physics, Huanghe Science and \\ Technology Colledge, Zhengzhou, P. R. China \\ adshuxian@163.com, b857931663@qq.com \\ *The corresponding author
}

Keywords: Linear algebra; Flipped classroom; Innovation; Mode

\begin{abstract}
Flipped classroom" teaching mode has become one of the effective means and methods to improve the quality of teaching and teaching efficiency. The traditional process of it changed the traditional education idea and teaching the class teacher centered, classroom interaction between teachers and students into the place, and through the promotion of students' autonomous learning ability and thinking ability and learning achievement. The research group will flip the classroom model used in linear algebra teaching, explored a set of specific methods and means, through the class, class, class design and interface of each stage, the knowledge transfer, construct, internalization, consolidate and expand, and achieved good results 。
\end{abstract}

\section{Introduction}

The flipped classroom is a kind of teaching form, which is based on the creation of the teaching video, which allows the students to study the teacher's explanation before or after class, and interact with each other in the classroom and realize the application of knowledge [1].

Flip the classroom is the crystallization of the modern information technology and the integration of classroom teaching, and the level of development of the modern information technology continues to improve, it provides the means of infinite possibilities for modern education teaching. It greatly affects the teaching mode of modern education and the reform of methods, has provided the infinite possibility for the innovation of modern education and teaching methods and means. It is because of the application of information technology in the field of education and teaching, making teaching as "the first scene of the traditional classroom teaching is facing a revolution, we must innovate the traditional classroom teaching mode to meet the challenge, flipping also came into being [2].

Flip the classroom is a kind of means, it is an effective way to reform the traditional classroom teaching. It can effectively increase the contact time between teachers and students by creating interactive and personalized, to enable students to responsible for their own learning environment, let the teachers become students around the "teaching practice", rather than the podium lectures "saints", it is a mixture of direct explanation and constructivist learning, the classroom teaching contents in a permanent archive, so as to help students review or makeup, do not because of students' absence, and affect the subsequent course of study. It created so that all students are actively learning atmosphere in the classroom, so that all students can receive individualized education.

The flipped classroom is conducive to students to create personalized learning content, improve their ability to solve problems and enhance students' inquiry activities in project to enhance the learning efficiency based on the change of students' learning so flipped classroom patterns and habits from many aspects. This has become a hot issue of domestic and foreign experts, research and exploration of education workers the existing in the attempt and exploration, the effect of classroom, effectively enhance the teaching effect has been recognized by scholars and educators, to study abroad started flipping the classroom early, accumulated rich experience, explore a variety of ways and means of teaching research and explore more and more. Educators are actively involved in the flipped classroom, activelyinvolved flipped classroom teaching mode applied in different periods, different disciplines, different types of teaching courses At the same time, we have achieved good teaching effect, and the 
majority of educators in our country are also active in the concept, strategies, methods, means, models and other aspects of exploration, and achieved some encouraging results [2,3].

The research group in April 2016 to get the linear algebra Henan Institute of Engineering key course construction project. The beginning of the project, the research group will actively participate in all members of linear algebra key course construction work, according to the specific characteristics of the course of linear algebra from the concept, mode, method, means, methods and other aspects of innovation and practice. This will flip the classroom the new teaching mode, try for the teaching of linear algebra, accurately grasp and understand the teaching mode of flipped classroom concept, ideas, ways and methods, and actively participate in the teaching process of this pattern, to discuss various aspects and from before class, in class, to explore and implement the design and convergence other aspects of after-school activities. In order to achieve before class, in class and after class teaching activities. The integration worked out a suitable linear algebra based on flip classroom teaching mode of curriculum characteristics Focus on the road of curriculum construction.

\section{Design and Application of Linear Algebra Flipped Classroom}

Iideas of the Design of Linear Algebra Reversal Classroom. The traditional teaching mode, pay more attention to the classroom teaching and imparting knowledge, while ignoring the knowledge transfer in the classroom before the design and research stage, and after review and consolidate knowledge and application, the main role of the students has been weakened. While the full attention of flipping the classroom before class, in class and after class cohesion, design activities, and strive to achieve before class, in class, the perfect fusion and integration. Based on the video link after class the main carrier, around a knowledge point or teaching system to carry out the complete teaching activities, fully use the modern educational technology and equipment, science curriculum design teaching, application. The 3D animation, virtual reality, multimedia technology, makes the abstract, macro, micro and so difficult to understand the knowledge points is displayed through the form of video, to enhance students' understanding of teaching content, grasp and The use of, and strive to do everyone can see, everyone can understand.

Linear algebra is a public basic course in university engineering majors, it is highly abstract and obscure, widely used in subsequent professional courses have. This feature requires us to linear algebra in the course, only to let the students can understand and grasp, but also improve the ability of application based on the project. So we focus on the following key points: (1) Service in the classroom before class learning, understanding and after-school review, taking into account the mobile learning and online learning; (2) Outstanding knowledge, scientific design, to explain thoroughly; (3) To video based teaching, taking into account other learning resources. The use of teaching methods[2-4].

Through the design and application of the flipped classroom teaching mode, try to do the following two aspects:

To Enable Students to Learn Self-Control. By flipping the classroom, students can use the teaching video, according to their own situation and control their own learning rhythm and time, and it is one of the key points and difficulties, to control the pace of learning, through repeated learning to understand, you can also use the a variety of social software or communication means, ask the teacher and classmates for help.

Enhanced Interactive Learning, and Make Learning Interesting, not to Flip the Classroom. Dull as ditch water interaction to enhance classroom teaching, let the teacher role from the presentation of the content, to study the coach, between teachers and students, between students, to have sufficient interaction and communication, which makes the teacher has the time of communication between teachers and students more fully, to achieve personalized learning and guidance. At the same time can also be among the students to establish their own collaborative learning group to help each other, learn from each other, mutual cooperation, common progress, further weakening the teachers as the only disseminators of knowledge, and make teachers become a guide to students' learning, the course of study into a meaningful activity, rather than a busy job. 
In the design and use of the flipped classroom teaching mode, we should strive to achieve the following four changes and four focus: from knowledge teaching to students' development change; change from teaching materials to teaching materials; from the focus on teaching to focus on the study of transition; teaching changes from traditional teaching to the new concept of the learning process; pay attention to the cultivation of students, active thinking, the cultivation of students' autonomous learning habits, cultivate students' cooperative spirit.

By flipping the classroom, as a teacher to talk less and to stimulate students to learn more, so that all students have something to do and move up, busy up.

The application of flipping the classroom this teaching mode should give full play to the timeliness and effectiveness of online interaction, homework and learning through online communication, immediate feedback in learning from and corrected in a timely manner, so as to understand the students of a certain knowledge to grasp the situation, and the overall situation of the whole study, so as to adjust the teaching schedule and the difficulty in a timely manner, and to develop individualized counseling program.

\section{Design of the Teaching Mode of Linear Algebra}

Flip the classroom must be based on the teaching objectives, teaching object, teaching content analysis and extraction, according to the actual needs of teaching, making teaching video collection and network teaching resources, the teacher demonstration video based, supplemented by courseware resources to students' homework exercises, supplemented by answering online, online testing, online feedback survey of autonomous learning activity.

Therefore, in the process of teaching in the process of flipping the classroom, to clarify the classroom and grasp the characteristics of flip flip classroom, in order to achieve the teaching structure of flip, by the students heard passive active learning flip, where teachers are teaching to guide the study process and facilitator turnover, by students is passive audience the table next to the active participants in the learning process of flip [2-5].

The design of the flipped classroom teaching mode, should be conducive to the construction and internalization of knowledge to students, make students before class learning, class interaction and collaboration between teachers and students, teachers and students of the status of converting interlaced fusion, stimulate the students' learning activities, mobilize students' learning initiative; should be beneficial to the students' individual differences and personalized learning to realize the stratified education and personalized learning. We should give full play to the advantages of modern information technology, create a relaxed learning environment.

\section{Design and Implementation Steps}

In order to realize the transfer of knowledge, internalize, consolidate and expand [6,7]., the course of linear algebra is realized through the task of passing the class before the class, the key tasks in the course and the expansion task after class.

Preparation before Class. According to the purpose and content of teaching needs, combined with the requirements of the syllabus, the teaching of the key and difficult to sort out, suitable for the presentation and teaching content.

Design and Production of Teaching Video. Considering the characteristics of linear algebra, in the production of the video should be short; teaching information clear, for each specific problem, should be focused and targeted; to be realistic as far as possible to increase the teaching process and field; due to the abstraction of linear algebra the content of the reasoning for every step of the process, should be as clear as possible, clear and coherent; create a good learning environment of information, do online $\mathrm{Q}$ $\&$ A, online discussion smoothly; video production for the key point, but also the treatment effect of Art (such as the use of special fonts, special colors special animation effects), the students can grasp the key and difficult points. 
Transfer of Knowledge Content. By teachers and students, interaction between students and students, students within the prescribed time, through online video, online FAQ, online discussion of autonomous learning process, realize the transfer of knowledge and skills of the teachers. Through the process of learning the teaching effect, and find the problem.

Internalization of Knowledge Absorption. Flip the classroom by reconstruction of students' learning process, thus the absorption and internalization of knowledge, to complete through the interaction between teachers and students in the classroom. Because the information transfer is students before class, the teacher provides video and online counseling, but also to understand the learning difficulties of students advance in the classroom to targeted counseling, so as to effectively promote the process of knowledge absorption and internalization.

Review Test. The students through the teaching video learning, whether to understand the requirements of the master content? Teachers can arrange several tasks in the video after the pass, to help students timely self detection, to determine their learning status, in the line of communication and consulting necessary, to facilitate the development of review and consolidate the plan, at the same time, the students and the time to answer the questions can be timely feedback to the teacher, the teacher timely grasp and understanding of student learning, in order to make the classroom interaction more targeted and effective.

To Consolidate and Develop Students in the Learning Process. Through the understanding of the situation, teachers can focus on the comment, can show a good job through the network, not only play the exemplary role, and enable students to further consolidate and improve the knowledge point. At the same time, teachers can expand according to their content the master degree of collecting the necessary learning resources, set up necessary to expand learning tasks, to realize the application of linear algebra in the follow-up courses and lay a solid foundation for [7].

\section{Cases Study on the Classroom Teaching Model of Linear Algebra}

Flipped Classroom Teaching Case. The teaching content to "elementary transformation method of matrix inversion" as an example, to carry out the exploration and implementation of flipping the classroom, to further confirm the validity of the flipped classroom teaching mode on the teaching of linear algebra courses, the research group selected two experimental classes to carry out teaching and research. In the practical teaching process we pay attention to the collection and analysis of relevant feedback information, to understand the students of the new teaching mode of acceptance. Through the comparison of the empirical analysis, we found that the students in the learning attitude, learning efficiency, learning effect, interest level, class and homework, have achieved positive results.

Concrete Process. We have been in the early use of screen recording software and courseware, making a detailed teaching video, the students also has the ability to use computer network or other equipment of autonomous learning, and self-regulated learning, we carry out some necessary guidance.

Analysis of Teaching Content, Teaching and Production: the inverse matrix in the elementary transformation of the teaching unit, we invite experienced, excellent teachers to make full preparation, the successful completion of the video production. This paper introduces the elementary transformation transformation in matrix, and the elementary transformation of matrix into unit matrix that defines the concept of equivalence matrix and the theorems are given for the elementary transformation of Matrix Simplification, and then leads to the method of solving inverse matrix. And the attention points in the process of learning difficulties, focus, confusion, examples and exercises related thinking and short answer, set the relevant clearance task for the self detection effect.

Activity before Class: use modern communication and social networking means, the teaching content to students, autonomous learning by the students before class, and complete the relevant questions and short answer questions. According to the requirements of research group of teachers through the Internet and social means, at any time online to students autonomous learning in the process of question answer and that necessary, and the common problems encountered good students in the learning process of the necessary documents. 
Class Activities: according to the students autonomous learning before class in the process of facing some common problems or personal problems, typical explanations and tips, and then by the students to independent research and discuss the form to complete the relevant work.

After-school Activities: the teachers review of after-school homework, the excellent work through the network of public display. By teachers upload the development of the theory of knowledge or training tasks, from the students finish their training tasks.

\section{Information Feedback and Effect Analysis}

After the experimental teaching, we collected the students feedback information for recognition of the extent of this kind of teaching mode and the effect of the network through: (1) The form of new, more attractive, improve learning autonomy; (2) To focus on difficult or difficult problems, can be independent of in order to improve the effect of repeated learning, consolidate the knowledge and understanding; (3) For questions and questions to consolidate the knowledge through the task can be completed well, and improve the learning effect; (4) Outstanding job display can play a very good role model; (5) Between the network in students, the interaction between teachers and students, realize personalized counseling, improve the teaching effect, make every student leave no doubt master knowledge; (6) The expansion of knowledge and make students broaden their horizons, to broaden the knowledge and improve the Learning interest, laid the foundation for the prospective study.

We can use the following statistical methods to deal with the results of empirical analysis, and then get the results of different modes of teaching data, and its effect is analyzed and compared:

$$
\begin{aligned}
& \chi^{2}=\sum_{i=1}^{\mathrm{k}} \frac{n}{p_{i}}\left(\frac{f_{i}}{n}-p_{i}\right)^{2} \\
& s_{x y}=\sum_{i=1}^{n} X_{i} Y_{i}-\frac{x-\mu}{n}\left(\sum_{i=1}^{n} X_{i}\right)\left(\sum_{i=1}^{n} y_{i}\right) \\
& r=\frac{\sum_{i=1}^{n} X_{i} Y_{i}}{\sqrt{s_{x x} \sum_{i=1}^{n} X_{i}^{2}}}-\frac{X_{i} Y_{i}}{\sqrt{\sum_{i=1}^{n}\left[\sum_{i=1}^{n} X_{i}^{2}-\left(\sum_{i=1}^{n} X_{i}\right)^{2} / n\right]\left[\sum_{i=1}^{n} y_{i}^{2}\right]}}
\end{aligned}
$$

Table 1 gives the teaching effectiveness index of each course under different teaching modes:

Table 1 Flipped classroom teaching mode effect index empirical analysis table

\begin{tabular}{|c|c|c|c|c|c|c|}
\hline \multirow{2}{*}{ Curriculu } & \multicolumn{2}{|c|}{ Higher Mathematics } & \multicolumn{2}{c|}{ Linear Algebra } & \multicolumn{2}{c|}{ Probability Statistics } \\
\cline { 2 - 7 } & $\mathrm{N} \mathrm{M}$ & F M & N M & F M & N M & F M \\
\hline Class 1 & 83 & 91 & 90 & 94 & 87 & 85 \\
\hline Class 2 & 74 & 84 & 86 & 90 & 83 & 90 \\
\hline Class 3 & 89 & 95 & 78 & 87 & 76 & 82 \\
\hline Class 4 & 76 & 89 & 73 & 81 & 79 & 91 \\
\hline Class 5 & 65 & 82 & 79 & 86 & 75 & 90 \\
\hline Class 6 & 70 & 85 & 81 & 92 & 88 & 94 \\
\hline
\end{tabular}

As can be seen from table 1, the flipped classroom teaching mode is obviously better than the ordinary teaching mode. 
On the whole, the experimental teaching in the flipped classroom is more integrated into the teaching, learning information, improve the efficiency of teaching and learning, to achieve the desired objectives, and received a satisfactory effect.

\section{Conclusions}

The modern information science and technology innovation study way for job seekers to provide unlimited innovation in teaching. Teachers flipped classroom teaching mode, it is an attempt at using modern information technology innovation of science teaching, it greatly improves the teaching efficiency and effectiveness, making access to information and communication have changed revolutionary change. This model realizes before class, in class and after class cohesion, integration of teaching, to pass through before class, in class and after curing development, realize the construction and internalization of knowledge. The first step, the practice also proves its effectiveness and operability.

Although there is more to stay in the stage of theoretical research, model design and demonstration stage, but more and more educators are trying in various disciplines, various stages on the practice of this model, I believe that with the continuous promotion and continuous improvement in practice, this model will show a strong vitality.

\section{Acknowledgements}

This work was supported by the Ph.D. Foundation of Henan University of Engineering (No. D2010012).

\section{References}

[1] "Flipped classroom" teaching model [J]. Dream Education.2015. (3): 36-40.

[2] Liu Rui. The design and practice of the "flipped classroom" teaching model based on the micro course [J]; modern education technology, 2015.Vol.24 No.5:69-72..

[3] Zhong Xiaoliu, Song Shuqiang, and, research on the instructional design based on the concept of flipped classroom [J], open education research, 2016 (1): 58-64.

[4] Zhu Hongjie, Zhou Zan, flipped classroom and its effective implementation strategy [J], audio visual education research, 2016 (8): 79-83.

[5] Li Hailong, Deng Minjie,, design and application of task based classroom teaching model [J], modern educational technology, 2016 (9): 46-51. (in Chinese) .

[6] Lu Qiang, flip the classroom of Cold Thinking: Politics and reflection [J], audio-visual education research, 2016 (8): 91-97. 